Aguas profundas, aguas durmientes. Ricardo Warecki y el paisaje cultural del río Elisabet Veliscek

Boletín de Arte (N. 18), e004, septiembre 2018. ISSN 2314-2502

https://doi.org/10.24215/23142502e004

Facultad de Bellas Artes. Universidad Nacional de La Plata

\title{
AGUAS PROFUNDAS, AGUAS DURMIENTES \\ RICARDO WARECKI Y EL PAISAJE CULTURAL DEL RÍO
}

\section{DEEP WATERS, DORMANT WATERS}

RICARDO WARECKI AND THE CULTURAL LANDSCAPE OF THE RIVER

\section{Elisabet Veliscek \\ elisabet-veliscek@hotmail.com}

Centro de Investigaciones del Arte Argentino y Latinoamericano. Universidad Nacional de Rosario. Argentina

Recibido: $14 / 2 / 2018$

Aceptado: 8/6/2018

\section{RESUMEN}

El agua y la naturaleza constituyeron asuntos reiterados en la producción artística de Ricardo Warecki durante los años de entreguerras y de posguerra. El río Paraná se transforma en el argumento de escenarios donde predomina la quietud de un paisaje en el que hombres y mujeres suspenden sus actividades cotidianas para descansar. El artículo aborda la manera en que Warecki descubre e imagina su entorno cotidiano a través de una serie de pinturas, dibujos y estampas que tienen por motivo escenarios naturales cuyos protagonistas son el espacio del río y la barranca, los medios rurales o la presencia de la arquitectura que ocupa territorios que transforman el aspecto visible del barrio y de la ciudad.

\section{Palabras clave}

Arte moderno; naturaleza y paisaje; río Paraná; Ricardo Warecki

\section{ABStRACt}

Water and nature were persistent issues in the artistic production of Ricardo Warecki during the interwar years and the post-war period. The Paraná River becomes the argument of scenarios where the stillness of a landscape in which men and women suspend their activities to rest prevails. The article analyzes the way in which Warecki discovers and imagines his daily surroundings through a series of paintings, drawings and prints that have as motive natural scenarios whose protagonists are the space of the river and the ravine, the rural areas, or the presence of the architecture that occupies territories transforming the visible aspect of the suburb and the city.

\section{KEYWORDS}

Modern art; nature and landscape; Paraná River; Ricardo Warecki 
«Quiero permanecer lo más cerca que pueda de los bordes sin pasarme del límite. En la orilla ves toda clase de cosas que no puedes ver desde el centro.»

Kurt Vonnegut (1952)

El estudio del desarrollo de la modernidad capitalista del siglo XX centró su atención en la esfera metropolitana y urbana, ya sea europea o latinoamericana. Según sostiene David Frisby, «la investigación detallada del capitalismo agrario, incluso como escenario histórico, no constituyó un interés primordial, y mucho menos lo hizo el impacto de la modernización en la existencia rural» (2007, p. 179). Podría agregarse -también escasa fue la preocupación por la modernización y sus efectos en las periferias urbanas o en los límites de las ciudades en desarrollo - que a menudo experimentaron los cambios de manera desigual, bajo el impacto de otras realidades sociales y con una expansión arquitectónica e ingenieril más fragmentada y ecléctica. Rosario, la ciudad del sur de Santa Fe, como alguna vez fue señalada por Lisandro de la Torre, nunca llegó a convertirse en metrópoli, aunque absorbió con rapidez los cambios que fueron modificando la construcción de su paisaje social y urbano.

La transformación incesante configuró el aspecto de una ciudad que hacia 1910 poseía cerca de doscientos mil habitantes, de los cuales casi la mitad eran inmigrantes de distintas nacionalidades, convertida en un polo industrial y financiero, pero carente de un pasado monumental, de una tradición establecida y de un gusto cultural afianzado. El destino de ciudad próspera y cosmopolita, creada por la fuerza del trabajo y el desarrollo de la industria, se asentaba en un modelo de nación inspirado en las ideas del progresismo liberal (Prieto y otros, 2010). Este escenario en constante cambio fue adquiriendo algunas de las características de la ciudad moderna capitalista, manifiestas en la inmensidad de las nuevas construcciones. Todo comenzó a volverse imponente: ${ }^{1}$ fábricas, puentes, máquinas, puerto, grandes almacenes y edificios departamentales que empezaron a extender el tejido urbano y a borrar los límites. Las reformas en la infraestructura y el proceso de modernización imprimían, sin embargo, un sentido de sospecha en las zonas menos favorecidas y en aquellos espacios que el progreso iba haciendo desaparecer. Asoma, así, un contraste entre la rapidez del cambio que impone una reducción de la vida útil de las personas y de las cosas; la aparición de una nueva cultura urbana cosmopolita, y la permanencia de ciertos valores rurales y de tradiciones autóctonas, de olvidados parajes que mantienen un silencio y una calma aparente, un ritmo lento y pesado.

Las tensiones y las contradicciones presentes en la vida sencilla - entre los límites de la ciudad donde predomina la naturaleza junto con formas materiales relativamente estables - y la nueva culturo del asfalto marcada por la fugacidad de la vida moderna van a ser motivos de representación estética para Ricardo Warecki² entre los años treinta y cincuenta. Este trabajo se detiene especialmente, en un conjunto de obras que bordean los confines de la ciudad, espacios físicos en donde el río suele tener una presencia sostenida como elemento que une la representación de la naturaleza y la dimensión histórica con el impacto de la técnica como instrumento de modernización económica y urbana. En este sentido, cabe preguntarse, ¿de qué manera aparece narrada la historia de la ciudad en estas imágenes?, ¿cómo el artista percibe e imagina su entorno cotidiano?, ¿en estos escenarios rurales y urbanos se descubren los efectos de la modernización? Esta indagación comporta una lectura hincada en las especificidades culturales del paisaje de la ciudad de Rosario y en el modo en que este fue percibido por un artista moderno que vivía en un barrio alejado del centro, cuya preocupación no era el paisaje en sí mismo sino la forma en que éste era habitado y configurado para ofrecer nuevos sentidos.

En estas imágenes el artista exhibe las zonas marginales de la sociedad moderna gravitando sobre los espacios cercanos a la barranca del río Paraná, cuyas aguas habían sido motivo de una tradición literaria de fuerte contenido folklórico. En ciertos textos de actitud crítica, la costa representaba la idea

1 Según Werner Sombart, la masa y el cambio constituyen elementos característicos en la delineación de la cultura metropolitana moderna (Frisby, 2007).

2 Ricardo Warecki (1911-1992) nació en Rosario. Artista autodidacta y periodista de profesión. Se desempeñó en el diseño gráfico, la ilustración y la publicidad, colaborando asiduamente en diversos diarios y revistas. Fue dibujante de la filial local de la AIAPE y miembro del Círculo de Prensa de Rosario, institución que se convirtió en refugio de agrupamientos antifascistas y de artistas modernos. Su obra pictórica presenta un rastro perceptible del universo gráfico que marcó el eje de su producción. 
del camino hacia otros mundos y alentaba la esperanza de un cambio posible, pero visto desde la lejanía. Además, el agua oscurecida del río y su vinculación con los márgenes sociales habitados por seres melancólicos y desposeídos había sido un tema transitado por Warecki en la serie de xilografías realizadas para el libro Lo barranco y el río (1944), de Abel Rodríguez (Veliscek, 2013). Sin embargo, su inclinación hacia la representación del río y sus entornos no fue exclusiva de dicha experiencia editorial, más bien constituyó un argumento reiterado y una preocupación constante a lo largo de su producción visual. En este sentido, el río, el agua e incluso la lluvia podían ser también considerados por el artista como fuente de pureza o como símbolo espiritual de la fertilidad y la exuberancia en contraste con las aguas durmientes y profundas que caracterizan el paisaje interior y el universo de la conciencia al igual que los vestigios urbanos. Allí, la imagen de la barranca como un accidente geográfico natural puede ser leída como un símbolo de los bordes sociales y culturales representados por el artista. Aquellos bordes a los que aludía el escritor norteamericano Kurt Vonnegut (1952), desde los cuales se podían ver toda clase de cosas grandes, inimaginables, que no se ven desde el centro. Junto con las escenas fluviales y los cursos de agua que conforman el medio natural de la ciudad, puede percibirse la incidencia de la luz y la atmósfera húmeda propia de la región del Litoral. Sobre todo en algunas de sus pinturas, como la figura solitaria sentada frente al tronco de un árbol con el horizonte del río hacia lo lejos, o las muchachas descansando sobre la barranca e incluso en los óleos sobre su esposa e hija y en ciertas ilustraciones, puede notarse un aire etéreo que impregna fragmentos de las obras. Pareciera como si la periferia surgiera componiendo una suerte de luz local. ${ }^{4}$ Se descubre una mirada hacia las tradiciones estéticas del paisaje europeo y latinoamericano desde finales del siglo XIX junto con un conocimiento de las técnicas pictóricas, para lograr ambientes luminosos y el valor otorgado al dibujo en la composición. Elementos que Warecki, probablemente, pudo haber conocido muy bien a través de su lectura del Tratado de Paisaje (1943), de André Lhote, artista reconocido por su desempeño como teórico y maestro de los becarios latinoamericanos en París. Este volumen, traducido directamente del francés por el crítico de arte Julio E. Payró, tuvo gran circulación en la Argentina desde su publicación en 1943 por la editorial Poseidón. A su vez, hay en estas imágenes una búsqueda expresiva sobre la visión natural y los tipos populares que habitan esos espacios y una voluntad de exhibir el río como verdadera arteria del horizonte cultural y social. La importancia del río aparece en el carácter navegable de sus aguas cuyas riberas han sido lugar de esparcimiento, de recogimiento solitario o de reunión y paseo, al menos en las imágenes seleccionadas. El momento dedicado al descanso luego de la jornada laboral emerge como un motivo insistente junto a las formas de la arquitectura y los objetos, como barcos y canoas, que van ocupando territorio y transformando el aspecto de estos parajes olvidados.

\section{LUGARES DE LA MENTE}

En una conferencia dictada por el pintor en la Asociación Amigos del Arte de Rosario, en junio de 1950 - dos años más tarde publicada en forma de artículo en el primer cuaderno Litorol-, señalaba sobre la destreza requerida para expresar la esencio del paisaje, más que su forma, tomando del católogo brindado por la naturaleza los sonidos y de colores característicos, aunque evitando la fidelidad de espejo del pintor naturalista. De esta manera, explicaba que las imágenes «se revelan desde adentro», «bañadas de su íntima poesía» (Warecki, 1952, s/p). Para el artista, la superación de la imitación exacta consistía en la forma de lograr la independencia para salvar el arte de la deshumanizoción. Frente a este concepto introducido por José Ortega y Gasset (1991), a mediados de los años veinte, Warecki se preguntaba: ¿no será el público el que está deshumanizado? Los intentos del artista de transmitir las propiedades físicas o la descripción geográfica del paisaje quedan registrados en su obra artística y en sus textos, en los que se revela la incidencia del impacto emocional y espiritual para captar la esencia del lugar y para transferir un sentido de pertenencia. En una exposición organizada por el British Museum, Kim Sloan (2007), curadora y responsable del área de conservación de acuarelas y dibujos de dicho museo, presentaba una selección de pinturas en acuarela realizadas entre la época victoriana y mediados del siglo XX. En su texto para el catálogo se refiere a los paisajes que evocan lugares de la mente recuperando el título de la colección de ensayos publicados en 1949 por el poeta y crítico Geoffrey Grigson. Cada dibujo y acuarela escogido

3 La representación de una luz propia aparece como una búsqueda constante en la pintura de paisaje de los países nórdicos entre finales del siglo XIX y mediados del XX (Rouse \& Nordal, 1995). 
para integrar la exposición se corresponde con una idea de construcción personal de la mente y la imaginación de su creador. La muestra incluye obras que transitan desde las interpretaciones coloristas y atmosféricas de los pintores de la hermandad prerrafaelita, pasando por las tendencias que dieron preeminencia a las variaciones lumínicas hasta las abstracciones de la realidad que ofrecieron una visión diferente sobre la percepción de la naturaleza. Este concepto, si bien utilizado para referir a un estilo de paisaje comúnmente despojado de humanidad, podría extenderse hacia aquellas obras del artista que perciben las periferias urbanas e industriales de un modo sensible, excediendo el mero registro descriptivo, para dar prioridad a una curiosa mirada que interpreta el sentido del lugar y de sus habitantes. En esas obras puede descubrirse, también, una significación subyacente que permite ofrecer nuevas lecturas hacia esa idea de un lugar puramente imaginario. Como bien señalaba el propio artista en su conferencia, la naturaleza formaba parte de un catálogo, un territorio geográfico siempre presente y, a la vez, un lugar de pertenencia. Con este sentido también pueden entenderse sus ilustraciones y sus dibujos sobre temas camperos, en los cuales a veces el lugar físico en que se inscriben gauchos, campesinos e indios puede resultar irreconocible a primera vista e, incluso, generar cierta sensación de extrañamiento. En ellos se introducen elementos y espacios comunes provenientes de la imaginación del artista que se vinculan con una propuesta estética e ideológica, donde la intención de reafirmar la identidad nacional, a través de figuras características, tiene una fuerza especial (Veliscek, 2015, 2016a).

Es interesante observar la manera en que los rasgos de la sociedad contemporánea, sus habitantes y sus tipologías se conectan con una particularidad del paisaje que consiste en exponer las huellas de su pasado. En efecto, la naturaleza fue culturalmente diseñada y modificada por el hombre desde tiempos antiguos y muchos artistas sintieron una atracción tan fuerte hacia determinados lugares que necesitaron representar con perseverancia sus transformaciones. El lento fluir del Paraná y sus entornos sociales fueron motivos que le permitieron a Warecki exhibir fragmentos de la vida cotidiana y el esparcimiento popular en una ciudad que había sido configurada teniendo el río como argumento. Las aguas oscurecidas fueron, también, antiguamente veneradas y representadas por los mesopotámicos y los egipcios, cuyas civilizaciones se desarrollaron sobre las riberas del río. Algunas de las acepciones que adquirieron tenían que ver con la fertilidad y la destrucción, dos formas visibles a través de la abundancia de los frutos de la tierra que podían ser fácilmente arrasados por las crecidas y las inundaciones que bañan el paisaje.

Como indicábamos, en sus imágenes la observación directa de la naturaleza se abre a los placeres de la imaginoción para alterar y para componer las visiones recibidas e incorporar elementos de la inventiva personal. Es así como el artista utiliza en estas obras [Figura 1] ciertas figuras de lo moderno pero con antecedentes lejanos en la historia de la cultura, entre ellas, la temática de las ruinas como sueño romántico ${ }^{5}$ en oposición al paisaje heroico urbano.

El bote de madera abandonado sobre las orillas del Paraná, destruido tal vez por el paso del tiempo, por una tormenta inesperada o por la desaparición de su dueño, asoma en una de sus ilustraciones realizadas en los primeros años cuarenta. Se distingue en ella la huella de una presencia lejana que imprime un aire de soledad y la sensación de estar ante un tiempo detenido, estático, como si la misma naturaleza se resistiera frente al avance de lo desconocido. La representación de barcos y de botes abandonados posee una larga tradición en la historia del arte, siendo especialmente recurrente en la pintura de paisajes del romanticismo europeo y estadounidense, que fusionaron la imaginación de lo bello con lo sublime, dotado de un atractivo intenso y seductor. Es posible que la poética de las ruinas haya interesado al artista como un tópico para aludir a un lugar abandonado e ignorado por la historia pero capaz de incitar la imaginación del explorador. Mientras la población se volvía cada vez más urbanizada y móvil, el pequeño bote de madera varado en el tiempo y el espacio alude probablemente a la relación con la tierra y el trabajo manual, desplazado por el desarrollo de la industrialización. Si bien en ciertas obras de Warecki estas alusiones relacionadas con la simbología de la destrucción podían estar presentes, el río permanece por lo general como una llanura apacible, casi domesticada, en donde está latente la historia de la ciudad. En estas interpretaciones se revela la mirada del creador como intérprete y como transmisor de percepciones y de sentimientos personales. 


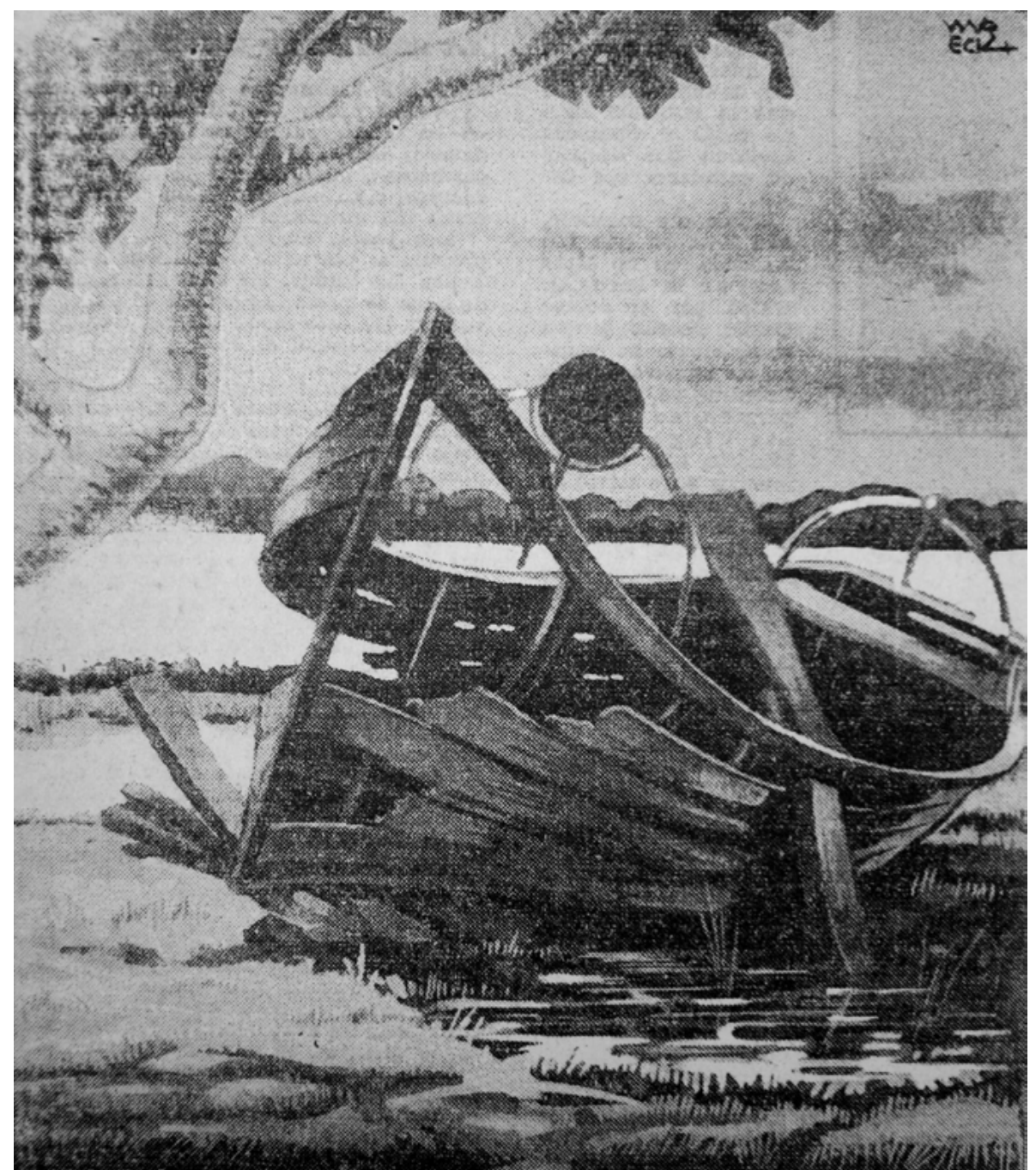

Figura 1. Ricardo Warecki (1941b). Ilustración para el texto «La barca», de Abel Rodríguez, diario Lo Copitol de Rosario

\section{BARRIO OBRERO}

Los arrabales marginados y los suburbios urbanos fueron considerados por los pintores motivos tan interesantes e igualmente hermosos como las calles nerviosas de la ciudad moderna. Entre esas imágenes, las periferias industriales sugieren las formas del nuevo paisaje artificial que va ocupando territorio en los límites de la ciudad. Allí puede ubicarse el antiguo barrio Refinería, que emerge hacia finales del siglo XIX como una zona obrera de singulares características. El barrio fue configurando su identidad a partir del asentamiento de trabajadores provenientes de los grandes talleres del Ferrocarril Central Argentino, ubicado a pocas cuadras, junto con los obreros y los estibadores del puerto, las fábricas y las industrias cercanas, con un dominio de depósitos, de muelles y de vías. El nombre del suburbio fue incorporado a partir de la instalación de la Refinería Argentina de Azúcar, de capitales alemanes, puesta en funcionamiento en 1889 (Campazas, 1997). La firma comenzó sus operaciones en medio de un gran entusiasmo de los propietarios de ingenios y se convirtió, en poco tiempo, en la mayor fuente de trabajo de la zona. Sin embargo, una variedad de factores, entre ellos, la irregularidad de las cosechas, las huelgas y el aumento de los impuestos (Guy \& Wolfson, 1988) confluyeron para desestabilizar su funcionamiento y para impulsar su desaparición en la década del treinta.

En un trabajo anterior habíamos sugerido que la xilografía Usina [Figura 2], realizada por Ricardo Warecki en 1944 y enviada al II Salón de Grabado organizado por el Museo Municipal de Bellas Artes Juan B. Castagnino, probablemente exhibiera una vista poco convencional de la Usina Sorrento (Veliscek, 2016b). No obstante, el enfoque del escenario y el aspecto exterior de las instalaciones 


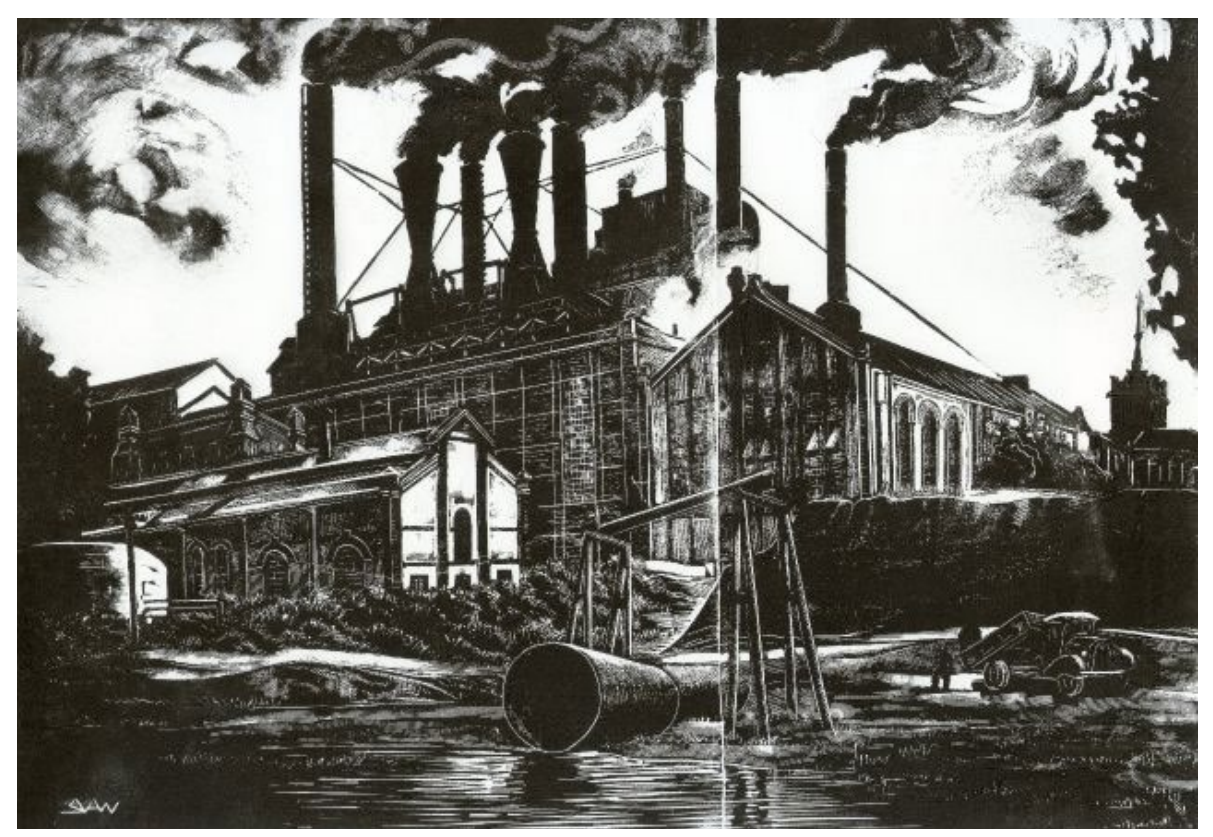

Figura 2. Ricardo Warecki (1944), Usina. Xilografía, 17 x 24 cm. Colección Ricardo Truffer-Warecki

parecen coincidir, más bien, con las vistas desde la barranca de las viejas fotografías y postales de la Refinería Argentina. Las enormes proporciones arquitectónicas del establecimiento con sus numerosos galpones y chimeneas humeantes, las hileras de ventanales iluminados en la noche o la zona del embarcadero y el playón de cargas componían una estampa del progreso industrial con el paisaje del río hacia el fondo. La multiplicación de talleres y la concentración de industrias parecían traslucir en imágenes aquella poesía del nuevo paisaje de mástiles urbanos surgido de las brumas, afirmándose en su inmensidad sobre el espejo de agua del río, como de hecho es posible ver en las fotografías de la Refinería tomadas hacia principios del siglo XX [Figura 3].

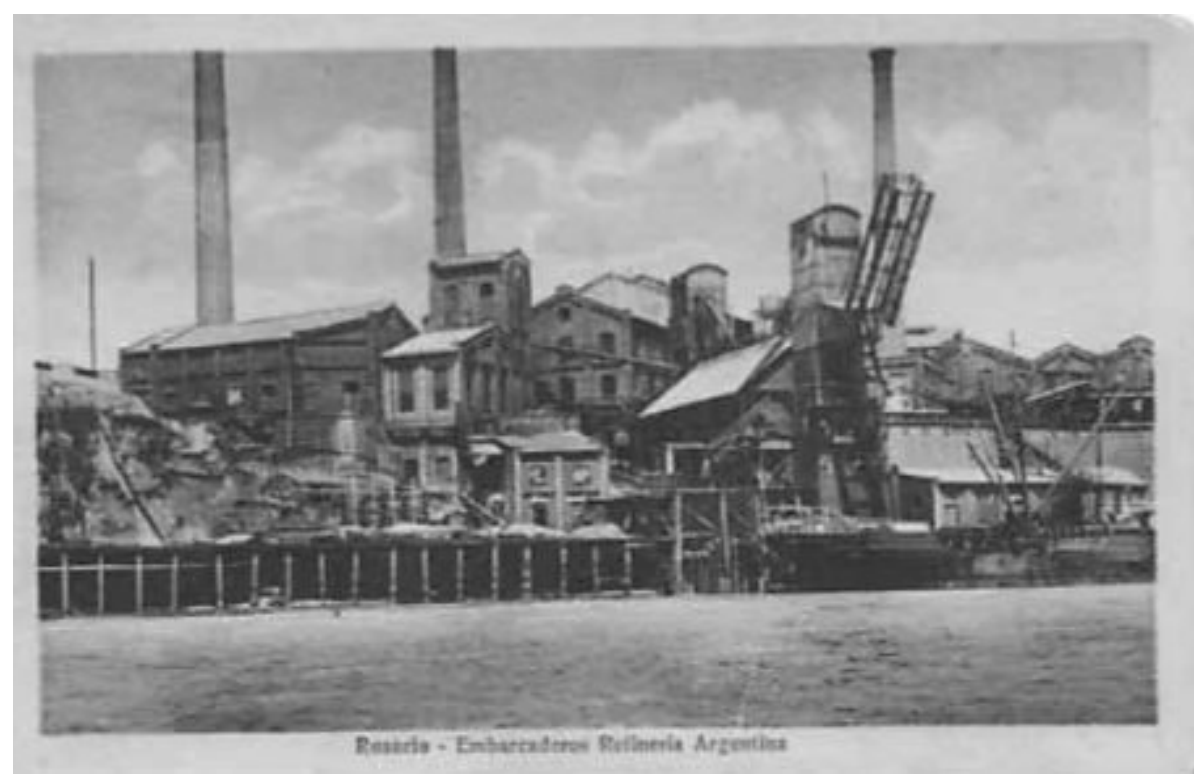

Figura 3. Embarcadero de la Refinería Argentina de Azúcar (ca. 1920). Archivo fotográfico Museo de la Ciudad

Según señala Agustina Prieto (2010), este despliegue industrial traía «a los cronistas anónimos reminiscencias de las grandes fábricas de las ciudades europeas» (p. 73). En el mismo sentido, un crítico apuntaba lo siguiente sobre la obra de Warecki: «El carbón, el cielo, el humo y el mismo edificio, encajan dentro de una perfecta armonía de líneas, y a través de esos elementos, se advierte, 
por dar una imagen exacta, la potencialidad fecunda del trabajo» (Lo Copital, 1944, s/p). Si bien la Refinería había cesado su funcionamiento para inicios de la década del treinta, es posible que el artista condensara en la obra sus intereses sobre las dramáticas y solidificadas periferias industriales ${ }^{6}$ que hacia los años cuarenta estaban en su apogeo en Rosario.

El desarrollo de la industria y la técnica había sido, además, una temática frecuente en el conjunto de su producción, como dejan entrever las ilustraciones aparecidas en distintos medios para publicitar herramientas y objetos electrónicos, estudios y empresas de arquitectura o compañías como la Sociedad Eléctrica de Rosario. La cultura técnica, un instrumento de modernización característicamente masculino - vinculado a los saberes de las capas medias de la sociedad, como la química e ingeniería, metalurgia y electricidad-, acompañó desde los años veinte otros procesos que presentaban un modelo de ascenso social basado en destrezas no tradicionales, como las prácticas manuales (Sarlo, 2004). Podrían pensarse esos motivos en el conjunto de representaciones que ponían en escena la figura del inventor divulgada en los manuales y las notas periodísticas, en las imágenes y en las publicidades, como las realizadas por el artista luego de la segunda posguerra. Sea como fuere, la xilografía de Warecki presenta una postal imaginaria de la industria, ya se trate de la vieja Usina Sorrento o de la Refinería Argentina, en plena actividad, con el cielo saturado de humo y de carbón, con obreros descargando bolsones de un camión que parecen figurillas en miniatura respecto a la enorme escala del paisaje, y con los pastizales que bordean los galpones y las instalaciones sobre el terreno desnivelado de la barranca. El equilibrio entre técnica y naturaleza parece caracterizar esta imagen en particular, diferenciándose de las analizadas anteriormente, en las que prevalece una mirada nostálgica sobre los confines de la ciudad. Es posible advertir la manera en que estas obras «traslucen conflictos latentes de la ciudad moderna como lugar de unas diferencias que se sedimentan en torno a dos figuras de su desarrollo decimonónico: la contradicción entre el centro y la periferia, entre la ciudad antigua y la moderna, y la existente entre la ciudad y el campo» (Marchán Fiz, 1986, p. 27).

Si bien Rosario carecía de un pasado medieval como tenían muchas capitales europeas que fueron transformadas mediante un proyecto de modernización urbana, el elemento antiguo podría estar presente, por ejemplo, en la cúpula de la torre ubicada hacia el fondo, en la derecha de la imagen. Una vez más, el artista exhibe una visión personal que mezcla componentes reales e imaginarios para aludir a un espacio que significó una gran fuente de empleo y un modelo del poder de la tecnología, la máquina y el desarrollo de la industria. Aquellos depósitos y chimeneas que se alzan potentes y altivos recortándose sobre el cielo matinal presentan un dibujo minucioso, en el que el juego de líneas va componiendo la estructura de la arquitectura con sus arcadas, enrejados y portones. Este interés por una técnica cuidadosa y detallada en sus grabados deriva en parte del uso del buril y de otras herramientas que permiten arrastrar líneas finas sobre una madera sólida como el viraró, comúnmente utilizada por el artista. La preferencia por este tipo de instrumentos de grabado implica que sus imágenes se diferencien notablemente del canto a los volúmenes geométricos de los silos y las fábricas de composiciones simplificadas y esquematizadas, como las que caracterizan a los precisionistas norteamericanos y a las estéticas racionalistas y puristas en la Europa de entreguerras.

\section{TIEMPO DE OCIO}

El acortamiento de la jornada laboral y el incremento del número de barrios distanciados del centro brindaron nuevas formas de sociabilidad popular y de tiempo libre, multiplicando las zonas destinadas al ocio familiar. Los espacios verdes y los balnearios definieron algunos lugares predilectos a los que se sumaron las prácticas deportivas y culturales, estas últimas en torno a la radio, el cine y la palabra escrita en sus diferentes expresiones. Las nuevas formas de concebir el descanso pueden advertirse en ciertas obras del artista en las que obreros, campesinos y figuras femeninas suspenden sus actividades para darle tiempo al reposo, la siesta o la lectura. Sin embargo, a diferencia de las imágenes que ponían en escena las formas de distracción familiar en el interior del hogar, típicas en la propaganda

6 Simón Marchan Fiz (1986) se refiere de esta forma a los paisajes de silos y fábricas metafísicos de Mario Sironi y a los pintores berlineses de la nuevo objetividad de los años veinte.

7 En ellas aparecen condensadas las estructuras jerárquicas tradicionales del mundo familiar: «El padre está sentado leyendo el diario o escuchando la radio, la madre se encuentra haciendo labores domésticas y los hijos, entre tanto, ocupados en sus tareas escolares» (Torre \& Pastoriza, 2002, p. 304). 
oficial y en los libros de lectura del peronismo, ${ }^{7}$ en Warecki los tipos populares aparecen ensimismados en sus pensamientos, concentrados en actividades como la lectura y la pesca, o simplemente tendidos sobre la hierba y la tierra, rodeados por el escenario fluvial o el medio agreste [Figuras 4 y 5].

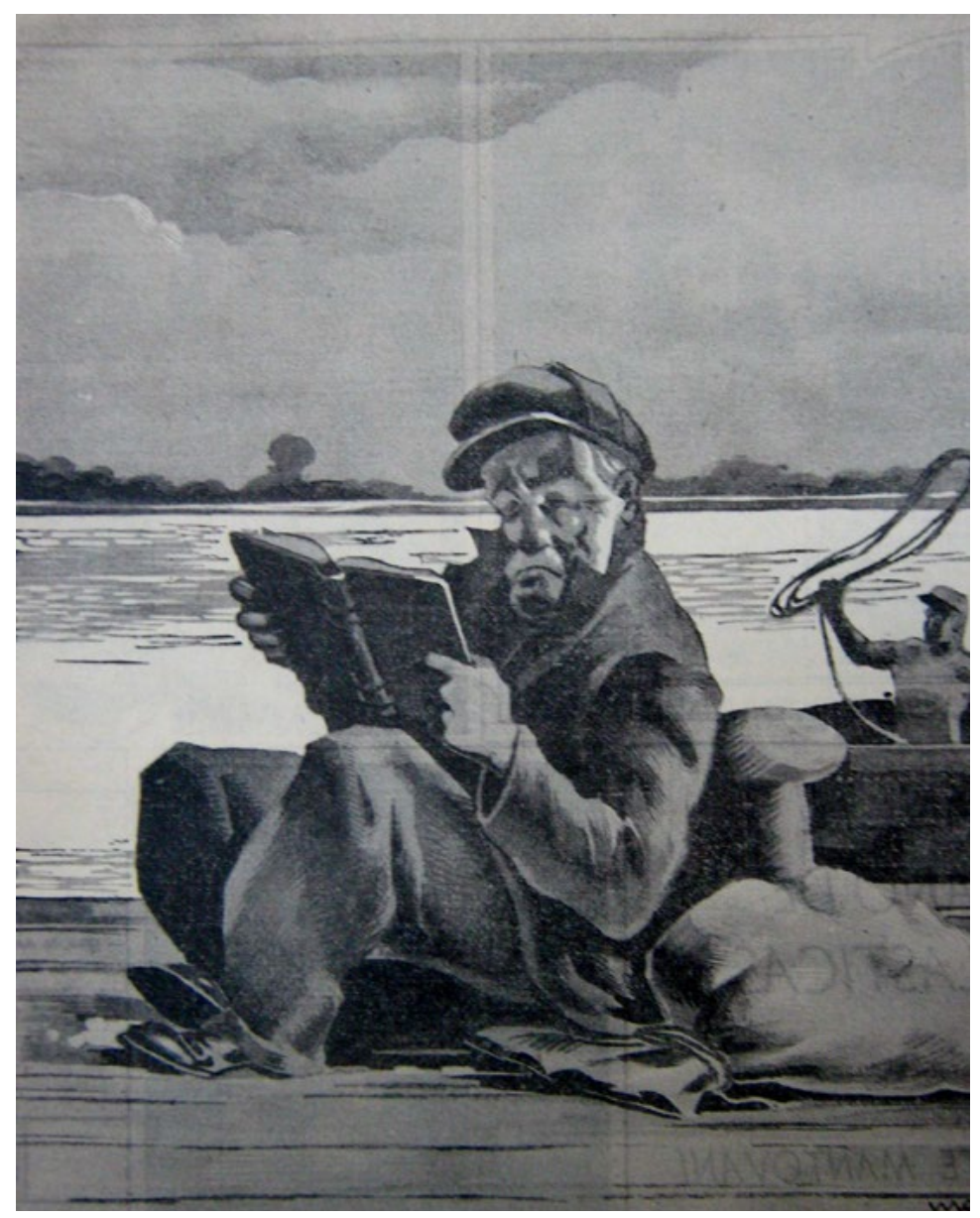

Figura 4. Ricardo Warecki (1941a). Ilustración para el texto «El hombre que leía a Kant», de Abel Rodríguez, diario La Capital, de Rosario

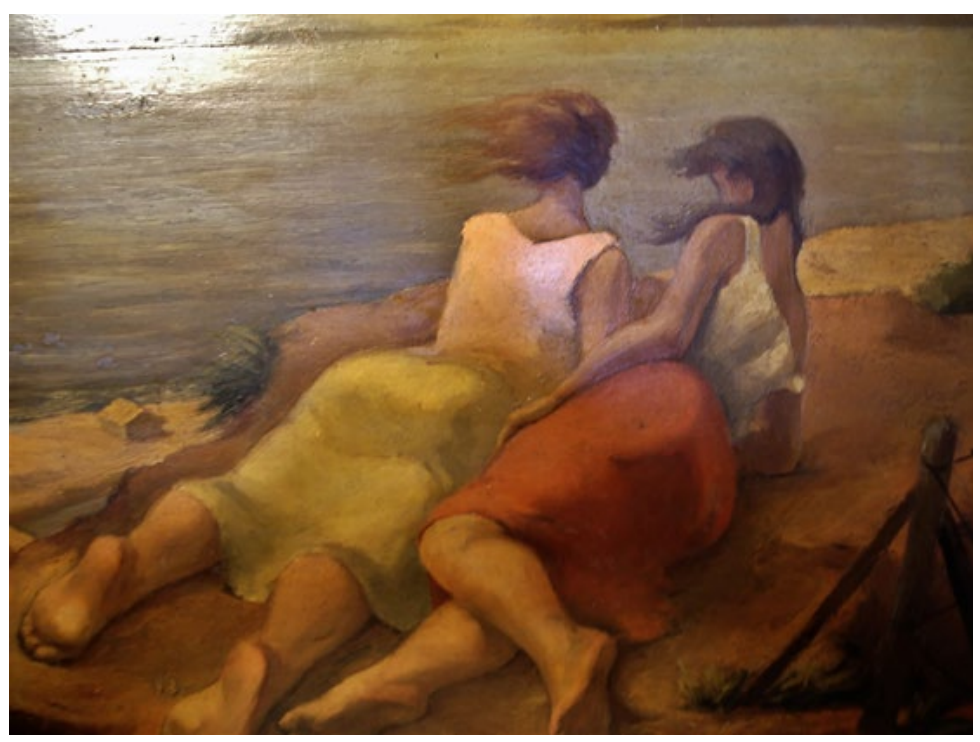

Figura 5. Ricardo Warecki (ca. 1945), Río. Óleo sobre madera. 49,5 x 63 cm 
Aquellos temas centrados en los márgenes que rozan la disponibilidad rural y el modo en que el artista representa dichos repertorios estéticos podrían explicarse debido a su simpatía inicial por el anarquismo, devenida en un interés por la política del radicalismo. Un desplazamiento de la representación política que fue habitual en el movimiento obrero y en el campo intelectual argentino de entreguerras, junto con la dominancia del sindicalismo en los espacios gremiales (Romero, 1990). En este sentido, la amistad del pintor con el escritor anarquista Abel Rodríguez le permitió, seguramente, permear ciertos espacios para construir redes de sociabilidad más extensas, incluida la esfera profesional. Entre las numerosas ilustraciones del artista aplicadas al diseño editorial y a los dibujos como acompañamiento de textos literarios se encuentran aquellas destinadas a los cuentos del escritor publicados en el diario Lo Copital. Uno de esos trabajos exhibe la figura de un hombre librado al azar, sumido en la indigencia por las contradicciones de la vida capitalista. La segregación espacial de la ciudad excluía a estos seres abandonados de las nuevas formas del ocio practicadas por los sectores acomodados, que se desarrollaban entre las zonas del bañado de los arroyos interiores y el Saladillo. El río Paraná quedó aislado hasta al menos la década de 1940, «debido a su emplazamiento sobre barrancas demasiado escarpadas, a las aguas profundas dedicadas a actividades portuarias y a la ausencia de inversión en estos espacios para la higiene y el ocio» (Roldán, 2008, s/p).

Hacia el sur de Santa Fe, la costa del río se eleva en altas barrancas que descienden en aguas de gran turbiedad, dando lugar a leyendas populares sobre bestias antropomorfas y espíritus de los que se han ahogado. La peculiaridad de este entorno natural con sus mitos y sus supersticiones que animaron una tradición literaria de contenidos folklóricos (Cardozo \& Spinassi, 1973), junto con los tipos populares como el pescador y el tropero de las islas, el palanquero y el baqueano de aguas, entre otros trabajadores del río, daban al paisaje un contorno pintoresco y una identidad especial. La orilla con el escenario de las islas a lo lejos puede concebirse, entonces, como una zona de esparcimiento popular y este aspecto es el que aparece insinuado en las imágenes del artista. Uno de los personajes del cuento mencionado alude a las características de estos parajes naturales: «Trataba de embeberme en el paisaje. El cielo de un azul inalterable y profundo contrastaba violentamente con las aguas parduscas del Paraná y con las islas llenas de recovecos y de un verde monótono» (Lo Copital, 1941b).

No se trata de un simple marco decorativo, en estas obras se perciben los intentos del artista por capturar con una visión propia formas de la identidad popular, entre ellas, el nuevo uso del tiempo libre mediante la lectura de libros baratos, el esparcimiento en parques y jardines naturales o en la zona de las barrancas y la ribera del portentoso Paraná. Las figuras aparecen observando desde las colinas las embarcaciones lucientes, pasando el tiempo bajo el sol estival o simplemente descansando de sus labores. El propio artista solía realizar largas caminatas por la orilla del río y podemos pensar cómo iba descubriendo en este trayecto la tierra que se mezcla con el agua, las viejas barcas olvidadas en la orilla y las siluetas de los pescadores costeros, herederos de la vida solitaria en la isla; escenarios y figuras que tantas veces le sirvieron de inspiración (Truffer-Warecki, 2014). ${ }^{8}$

La representación del verde, de la vida rural incontaminada y de la periferia industrial pueden considerarse, además, un contrapunto de las imágenes intimistas que tienen como protagonistas a su mujer, su hija y su sobrina como figuras melancólicas. En aquellos óleos el artista incorpora una mirada hacia la femineidad que busca elevar la belleza espiritual más que la sensualidad física y el hogar emerge como sostén del mundo familiar. Se disuelve allí el registro del paisaje para dar lugar a motivos de la existencia privada, aunque en paralelo continúa realizando apuntes de asuntos urbanos y naturales, algunos de ellos vinculados a la sencilla vida pastoral.

Estos motivos fueron tratados con insistencia por el artista, adquirieron cada vez nuevos significados y actualizaron sus sentidos, a veces relacionados con los textos literarios a los que aludía y en otras ocasiones vinculados a preocupaciones estéticas o a búsquedas personales. En todos los casos, incorporó una mirada subjetiva que interpretó el paisaje de la ciudad y sus márgenes a partir de componentes imaginarios combinados con elementos descriptivos para aludir a las contradicciones de la vida capitalista, representar los recodos olvidados por la sociedad moderna o exhibir la potencia de la industria y el poder del trabajo. Aquellos escenarios urbanos y naturales adquieren un sentido próximo a través de las vistas del Paraná, río grande semejante al mar, según la expresión

8 Su nieto recordaba los extensos paseos en compañía del artista. Entrevista con Ricardo Truffer-Warecki, febrero de 2014. 
indígena, celebrado como un dios protector de la riqueza y de los pueblos que habitan sus orillas (Prieto, 1973). El río era aquel espacio que condensaba diversas expresiones siempre presentes en la imaginación del artista: abría vías nuevas de comunicación y era depositario de actividades industriales, a la vez que sus barrancas se convirtieron en lugar de reunión o recogimiento solitario. Junto con las vistas fluviales, el suburbio que avanza hacia el campo transformando el aspecto del paisaje revela la miseria de los bordes y su contraste con lo nuevo, la cara más visible de la ciudad moderna que imaginó Ricardo Warecki en otras de sus obras.

\section{REFERENCIAS}

Campazas, A. (1997). Historio de los barrios de Rosario. Rosario, Argentina: Homo Sapiens.

Cardozo, L. y Spinassi, E. (1973). Las comunidades indígenas. Las artesanías, el folklore y lo mágico. En Poraná, el pariente del mar (pp. 321-392). Rosario, Argentina: Biblioteca.

Frisby, D. (2007). La ciudad comparada. Viena no es Berlín. En Paisajes urbanos de la modernidad. Explorociones críticas (pp. 179-200). Bernal, Argentina: UNQ/Prometeo Libros.

Guy, D. y Wolfson, L. (1988). Refinería Argentina, 1888-1930: límites de la tecnología azucarera en una economía periférica. Desarrollo Económico, 28(111), 353-373.

Lhote, A. (1943). Tratodo del paisaje. Buenos Aires, Argentina: Poseidón.

Marchán Fiz, S. (1986). Contominaciones figurativas. Imágenes de la arquitectura y la ciudad como figuras de lo moderno. Madrid, España: Alianza.

Ortega y Gasset, J. (1991). Lo deshumanización del arte y otros ensayos de estética. Madrid, España: Alianza.

Prieto, A. (1973). El Paraná y su expresión literaria. En Poraná, el pariente del mar (pp. 395-420) Rosario, Argentina: Biblioteca.

Prieto, A. et.al. (2010). Ciudad de Rosario. Rosario, Argentina: Editorial Municipal de Rosario.

Rodríguez, A. (1944). La barranca y el río. Rosario, Argentina: Círculo de Prensa de Rosario.

Roldán, D. (2008). Tiempo libre, ciudad e higiene. Las experiencias balnearias en Rosario, Argentina (18861940). Scripto Nova. Revisto electrónica de Geografía y Ciencias Sociales, 12 (262), s/p.

Romero, L. A. (1990). Buenos Aires en la entreguerra: libros baratos y cultura de los sectores populares. En D. Armus (Comp.). Mundo urbano y cultura popular. Estudios de Historia Social Argentina (pp. 39-89). Buenos Aires, Argentina: Sudamericana.

Rouse, Y. y Nordal, K. (1995). Luz del Norte (catálogo de exposición). Madrid, España: Museo Nacional Centro de Arte Reina Sofía.

Sarlo, B. (2004) [1992]. La imaginación técnica: sueños modernos de la cultura argentino. Buenos Aires, Argentina: Nueva Visión.

Sloan, K. (2007). Places of the Mind. British Watercolour Landscapes 1850-1950 (catálogo de exposición). London, England: Thames \& Hudson/The British Museum.

Torre, J.C. y Pastoriza, E. (2002). La democratización del bienestar. En J.C. Torre (Dir. de tomo), Nueva Historio Argentino. Los años peronistos (1943-1955) (pp. 257-310). Buenos Aires, Argentina: Sudamericana. 
Veliscek, E. (2013). El río, el barrio y el paisaje: grabados de Ricardo Warecki y Santiago Minturn Zerva hacia los años cuarenta. Separato, (18), 32-46.

Veliscek, E. (2015). Ricardo Warecki, el impacto de los nacionalismos y las perspectivas folklóricas. Avances. Revisto de Artes, (25), 361-375.

Veliscek, E. (2016a). Panteón de los héroes. Retratos de próceres e imaginario nacionalista en el círculo de la Prensa de Rosario. Avonces. Revisto de Artes, (26), 291-303.

Veliscek, E. (2016b). Salones de grabado en Rosario. Del Museo Municipal de Bellas Artes a la Asociación Amigos del Arte. Arte y Sociedad. Revisto de Investigación, (11), 1-12.

Vonnegut, K. (1952). El piono. Washington, Estados Unidos: Charles Scribner's Sons.

Warecki, R. (1941a). Ilustración para el texto «El hombre que leía a Kant», de Abel Rodríguez. Diario Lo Copital, s/p.

Warecki, R. (1941b). Ilustración para el texto «La barca», de Abel Rodríguez. Diario Lo Copital, s/p.

Warecki, R. (ca. 1945). Río [Pintura]. Concordia, Argentina: Museo Municipal de Artes Visuales de Concordia. Warecki, R. (1944). Usina [Xilografía]. Rosario, Argentina: Colección Ricardo Truffer-Warecki.

Warecki, R. (1952). La pintura, evasión y superación de lo imitativo. Naturalismo. Sensualismo. Humanismo. Litoral, (1), 49-58. 